\title{
Desain Fasilitas Jalan Yang Berkeselamatan Pada Tiga Sekolah Di Kecamatan Pasar Kemis Kabupaten Tangerang
}

\author{
${ }^{1}$ Indah Handayasari, ${ }^{2}$ Muh Mahmuda, ${ }^{3}$ Gloriani Novita C \\ ${ }^{1}$ Institut Teknologi PLN \\ ${ }^{2}$ Politeknik Transportasi Darat Indonesia-STTD \\ ${ }^{3}$ Politeknik Transportasi Darat Indonesia-STTD \\ Email: indah.handayasari@itpln.ac.id
}

\begin{abstract}
Abstrak
Penyedian fasilitas keselamatan merupakan hal mutlak yang harus dimiliki oleh setiap jalan baik berupa rambu dan marka jalan, trotoar dan lain sebagainya demi menjamin terciptanya rasa aman bagi pengguna jalan. Banyak fasilitas-fasiltas umum seperti sekolah letaknya tepat di pinggir jalan yang membutuhkan perhatian agar dapat memberikan keselamatan bagi para pelajar. Oleh sebab itu penelitian betujuan untuk mengetahui desain fasilitas jalan berkeselamatan pada tiga sekolah di kecamatan Pasar Kemis Kabupaten Tangerang. Penelitian ini mengacu pada ketentuan di PM No.16 Tahun 2016 tentang perencanaan desain fasilitas keselamatan. Hasil penelitian menemukan pada ruas jalan diketiga sekolah diperlukan fasilitas pejalan kaki berupa trotoar maupun fasilitas Penyeberangan. Disamping itu dibutuhkan pula adanya halte tempat pemberhentian kendaraan umum dan rambu-rambu dan marka jalan serta kelengkapan lainnya seperti Zona Selamat Sekolah (ZOSS). Penelitian juga menemukan bahwa pada ruas jalan di ketiga sekolah tersebut belum dibutuhkan penambahan jalur sepeda. Diharapkan Pemerintah maupun pihak terkait perlu mendukung, menyediakan dan mensosialisasikan perihal fasilitas jalan yang berkeselamatan baik dari masyarakat setempat, orang tua siswa terlebih pelajar.
\end{abstract}

Kata Kunci: Fasilitas, Jalan yang Berkeselamatan, Pelajar, Sekolah.

\begin{abstract}
The provision of safety facilities is an absolute thing that must be owned by every road in the form of signs and road markings, sidewalks and so on in order to ensure the creation of a sense of security for road users. Many public facilities such as schools are located right on the roadside that require attention in order to provide safety for students. Therefore, this study aims to determine the design of safe road facilities in three schools in Pasar Kemis sub-district, Tangerang Regency. This research refers to the provisions in PM No. 16 of 2016 regarding safety facility design planning. The results of the study found that on the roads in the three schools pedestrian facilities were needed in the form of sidewalks and crossing facilities. Besides that, it is also necessary to have a bus stop where public transportation stops and road signs and markings as well as other equipment such as the School Safety Zone (ZOSS). The study also found that there is no need for additional bicycle lanes on the roads in the three schools. It is hoped that the Government and related parties need to support, provide and socialize about safe road facilities from the local community, parents of students, especially students.
\end{abstract}

Keywords: Facilities, Safe Roads, Students, Schools

\section{A. PENDAHULUAN}

Transportasi sebagai urat nadi sekaligus tulang punggung roda perekonomian yang menguasai hajat hidup suatu bangsa dalam rangka penyelenggaraan arus distribusi barang dan manusia, tentunya dibutuhkan sistem pelayanan terpadu dalam pengelolaan dan pemanfaatan segala sumber daya yang ada secara integral dan profesional agar terwujudnya sistem transportasi 
yang paripurna. Terkhusus pada transportasi darat yang merupakan alat transportasi yang sangat dibutuhkan dalam distribusi perjalanan orang dan barang, salah satu pengguna terbanyak transportasi adalah aktivitas pendidikan di sekolah. Oleh karenanya sangat diperlukan adanya keikutsertaan dan intervensi pemerintah sebagai regulator yang memberikan bimbingan, pengaturan dan pembinaan sehingga transportasi dapat diselenggarakan secara tertib, teratur, aman, nyaman dan lancar sesuai dengan amanat ungdang undang. Terdapat empat hal yang bisa dijadikan tolak ukur dalam melakukan penilaian transportasi di suatu daerah yaituh keselamatan, keamanan, keterjangkauan, dan kenyamanan dalam penyelenggaraan transportasi yang ada khususnya penyelenggaraan fasilitas jalan yang berkeselamatan.

Kabupaten Tangerang merupakan bagian dari wilayah administratif Provinsi Banten. Kabupaten Tangerang memiliki luas wilayah 959,61 km² yang terbagi menjadi 29 kecamatan yg dibagi lagi menjadi 28 kelurahan dan 246 Desa. Kabupaten Tangerang khususnya yang berlokasi di Kecamatan Pasarkemis, tepatnya di Kelurahan Pasar kemis sebagai salah satu bagian dari pusat tarikan berupa kawasan Pasar Harian yang menjadi bagian dari daerah mobilitas masyarakat dan lalulintas yang cukup tinggi. lokasi pendidikan yang terletak di Kecamatan Pasar Kemis ditandai dengan adanya tata guna lahan berupa lingkungan sekolah yang terdiri dari 3 sekolah dengan akses ruas Jalan raya Pasar Kemis dengan jumlah siswa sebanyak 3263 siswa. Lokasi SDN Kutajaya I dan SMP I Pasar Kemis yang saling berdekatan berada pada jalan Kolektor dengan tipe jalan 2/2 UD yaitu Jalan raya Pasarkemis dengan V/C Ratio sebesar 0,56. Sedangkan untuk SDN Sukaasih I Lokasi penelitian di Jalan raya Pasar Kemis pada jalan kolektor dengan tipe jalan 2/2 UD dengan V/C Ratio sebesar 0,68. Jalan Raya Pasar Kemis yang menjadi akses utama menuju tiga sekolah tersebut merupakan sebuah jalan kolektor primer dengan tipe 2/2 UD. Jika tidak didukung dengan fasilitas Penyeberangan yang baik khususnya bagi pelajar pada lokasi Pendidikan Kecamatan Pasar Kemis, maka hal tersebut sangat beresiko terhadap keselamatan para pelajar.

Sebagai salah satu lokasi pendidikan di Kecamatan Pasar Kemis, lokasi ini dinilai kurang ramah terhadap pejalan kaki. Hal ini ditandai dengan banyaknya pelajar yang melintas pada badan jalan pada saat pagi dan siang hari dimana jam sekolah berlangsung, ditambah lagi volume lalu lintas baik. Sepanjang Jalan raya Pasar Kemis maupun tepat berada di depan gerbang sekolah yang berdasarkan hasil survei menunjukkan angka yang sangat signifikan terhadap kecepatan dan volume lalu lintas setiap harinya yang selanjutnya bedampak pada menurunnya kapasitas jalan serta sangat beresiko tinggi terhadap keselamatan anak sekolah. Selain itu, banyak kendaraan pengantar siswa yang berhenti dibadan jalan (on street) menghambat pergerakan siswa karena ruang jalan yang terpakai oleh para pengguna kendaraan yang berhenti pada saat mengantar pelajar menuju sekolah. Selain itu, tidak adanya perlengkapan jalan baik rambu maupun marka pada lokasi pendidikan Kecamatan Pasar Kemis menyebabkan kurang terjaminnya keselamatan bagi pelajar, khususnya pelajar berusia dibawah 12 tahun yang masih membutuhkan pengawasan dan sosialisasi khusus dalam berlalu lintas.

Oleh karena itu, dibutuhkan adanya fasilitas jalan yang berkeselamatan khususnya pada kajian penelitian karena masih banyak anak sekolah yang rentan menjadi korban kecelakaan. Menurut data Polres Kab. Tangerang, pada tahun 2016 hingga tahun 2018, ada sekitar 130 kejadian kecelakaan lalu lintas yang melibatkan pelajar sebagai korban kecelakaan lalu lintas dengan persentase sebesar 13\% dari total 1005 kejadian kecelakaan di Kabupaten Tangerang.

Dalam menentukan desain fasilitas, maka dapat dilihat dari moda yang dipilih serta cara para pelajar melakukan perjalanan ke sekolah. Dibutuhkan jarak maksimal yang dapat ditempuh oleh pejalan kaki, pengguna sepeda, serta fasilitas sarana bagi pengguna angkutan umum seperti halte pada setiap sekolah. Jika fasilitas jalan yang berkeselamatan - khususnya di lingkungan 
sekolah dapat diwujudkan, maka keamanan dan keselamatan para pelajar dapat lebih terjamin. Oleh karena itu penulis mengambil tema Kertas Kerja Wajib yang kaitannya mengenai keselamatan berlalulintas dengan judul "Desain Fasilitas Jalan Yang Berkeselamatan Pada Tiga Sekolah Di Kecamatan Pasar Kemis Kabupaten Tangerang."

\section{B. METODE}

Desain fasilitas jalan yang berkeselamatan pada tiga sekolah dikonsentrasikan pada desain fasilitas untuk siswa dalam melakukan pergerakan pada akses yang aman dan selamat. Analisis ini bertujuan agar para pelajar dapat melakukan aktivitas khususnya berada pada akses gerbang sekolah memperoleh fasilitas keselamatan dengan aman dan selamat baik dengan berjalan kaki maupun menggunakan moda angkutan. Hasil pengamatan dilapangan dengan mengidentifikasi permasalahan-permasalahan dan merumuskan masalah yang ada sehingga mempermudah dalam pengumpulan data untuk penelitian. Data yang dibutuhkan berupa data primer dan data sekunder. Data primer meliputi rute yang digunakan, moda yang digunakan, asal tujuan inventarisasi jalan, data kecepatan ruas jalan diwilayah studi, serta invetarisasi fasilitas keselamatan pada ruas jalan diwilayah studi. Sedangkan data sekunder yang dibutuhkan meliputi data alamat siswa, jumlah siswa dari tiap sekolah, serta data fatalitas kecelakaan dari Polres Kabupaten Tangerang. Berdasarkan dari data yang telah terkumpul selanjutnya dilakukan analisis kebutuhan fasilitas keselamatan sesuai kebutuhan diwilayah studi dengan mengacu pada ketentuan di PM No.16 Tahun 2016 tentang perencanaan desain fasilitas keselamatan.

\section{HASIL DAN PAMBAHASAN}

\section{Analisis Kinerja Lalulintas}

Kinerja lalu lintas dapat dipengaruhi dengan adanya perhitungan dari faktor arus lalu lintas pada ruas jalan tersebut, dan juga dari faktor-faktor penyesuaian yang mempengaruhi kapasitas jalan tersebut.

Tabel 1. Perhitungan Kapasitas Ruas Jalan

\begin{tabular}{|c|c|c|c|c|c|c|c|c|c|c|c|c|c|}
\hline $\begin{array}{l}\text { NAMA } \\
\text { JALAN }\end{array}$ & $\begin{array}{l}\text { PANJANG } \\
\text { LINK } \\
\text { (KM) }\end{array}$ & $\begin{array}{r}\text { FUNGSI } \\
\text { JALAN }\end{array}$ & $\begin{array}{c}\text { TIPE } \\
\text { ARAH }\end{array}$ & $\begin{array}{r}\text { LEBAR } \\
\text { LAJUR } \\
\text { EFEKIIF } \\
\text { (M) }\end{array}$ & $\begin{array}{l}\text { MEDIAN } \\
\text { (M) }\end{array}$ & $\begin{array}{l}\text { HAMBATAN } \\
\text { SAMPING }\end{array}$ & $\begin{array}{l}\text { FAKTOR } \\
\text { PEMISAH } \\
\text { (FCsp) }\end{array}$ & $\begin{array}{l}\text { FAKTOR } \\
\text { HAMBATAN } \\
\text { SAMPING } \\
\text { (FCsf) }\end{array}$ & $\begin{array}{l}\text { FAKTOR } \\
\text { UKURAN } \\
\text { KOTA } \\
\text { (FCCS) }\end{array}$ & $\begin{array}{l}\text { FAKTOR } \\
\text { LEBAR } \\
\text { MASUK } \\
\text { (FCW) }\end{array}$ & $\begin{array}{c}\text { KAPASITAS } \\
\text { DASAR } \\
(C 0)\end{array}$ & $\begin{array}{c}\text { KAPASITAS } \\
\text { TOTAL } \\
\text { (C) }\end{array}$ & $\begin{array}{c}\text { V/C } \\
\text { RATO }\end{array}$ \\
\hline \begin{tabular}{|c|} 
L. Raya PS. \\
Kemis(SD \\
Kutajaya I)
\end{tabular} & 150 & $\begin{array}{c}\text { Kolektor } \\
\text { Primer }\end{array}$ & $2 / 2 \mathrm{D}$ & 7 & 0 & M & 1 & 0,92 & 1,04 & 1 & 2900 & 2774,72 & 0,56 \\
\hline \begin{tabular}{|c|} 
JL. Raya \\
PS.Kemis(SM \\
PI PS.Kemis
\end{tabular} & 150 & $\begin{array}{l}\text { Kolektor } \\
\text { Pimer }\end{array}$ & $2 / 2$ UD & 7 & 0 & M & 1 & 0,92 & 1,04 & 1 & 2900 & 2774,72 & 0,56 \\
\hline $\begin{array}{c}\text { JL. Raya } \\
\text { PS.Kemis(SD } \\
\text { SUKAASIH I) }\end{array}$ & 200 & $\begin{array}{l}\text { Kolektor } \\
\text { Primer }\end{array}$ & $2 / 2 \mathrm{UD}$ & 6 & 0 & M & 0,97 & 0,92 & 1,04 & 0,87 & 2900 & 2341,58 & 0,68 \\
\hline
\end{tabular}

\section{Sumber Hasil analisis}

Menurut Global Road Safety Partnership Indonesia (2015), kecepatan merupakan sebuah faktor resiko penting kecelakaan pejalan kaki dan bahwa tumbukan dengan kecepatan di atas 30 
$\mathrm{km} / \mathrm{jam}$ meningkatkan kemungkinan luka parah atau kematian. Pada zona pendidikan dengan jumlah siswa yang banyak melakukan perjalanan pergi dan pulang untuk menyusuri jalan dan menyeberang jalan, dimana harus diimbangi dengan tingkat keselamatan yang ditinjau dari kecepatan kendaraan yang melintas. Dengan tujuan adanya pembatasan kecepatan apabila memang kecepatan pada ruas jalan itu masih kurang aman bagi pelajar yang berjalan kaki. Untuk mendapatkan informasi kecepatan rata-rata pada ruas jalan yang terdapat pada zona pendidikan, maka diambil data dari hasil survei SPOT SPEED Setelah dilakukan survai, maka diperoleh data kecepatan pada tiap ruas yang dapat dilihat pada table berikut:

Tabel 2 Kecepatan Ruas pada Lokasi Penelitian

\begin{tabular}{|l|l|l|c|}
\hline $\begin{array}{l}\text { N } \\
\text { o }\end{array}$ & Lokasi & Nama Jalan & $\begin{array}{l}\text { Kecepatan } \\
(\mathbf{k m / j a m})\end{array}$ \\
\hline 1 & $101-$ & JL. Raya PS. Kemis (SD Kutajaya I) & 32 \\
\hline 201 & $\begin{array}{l}201- \\
301\end{array}$ & JL. Raya PS. Kemis (SMP I PS. Kemis) & 31 \\
\hline 3 & $\begin{array}{l}601- \\
701\end{array}$ & $\begin{array}{l}\text { JL. Raya PS. Kemis (SD SUKAASIH } \\
\text { I) }\end{array}$ \\
\hline
\end{tabular}

Sumber hasil analisis

Berdasarkan Tabel 2 dari survei SPOT SPEED pada ruas jalan dengan tipe sistem 2/2 UD diperoleh hasil kecepatan rata-rata pada Jalan Pasar Kemis (SD Kutajaya I dan SMPN I Ps.Kemis) yaitu sebesar $32 \& 31 \mathrm{~km} / \mathrm{jam}$. Sesuai dengan ketentuan kecepatan kendaraan pada ruas jalan tersebut harus berada dibawah angka selamat yaitu $30 \mathrm{~km} / \mathrm{jam}$. Maka perlu dilakukan penanganan pada ruas Jalan tersebut untuk menurunkan kecepatan kendaraan yang melintas.

\section{Penentuan Fasilitas Jalan kaki}

Fasiltas pejalan kaki meliputi trotoar dan fasilitas Penyeberangan orang. Dalam menentukan fasilitas trotoar dan fasilitas Penyeberangan orang yang tepat maka perlu dilakukan survai agar fasilitas yang dipenuhi sesuai dengan ketentuan dan kebutuhan dari pejalan kaki itu sendiri. Tujuan dilakukannya survai pejalan kaki ini adalah untuk mengetahui berapa besar jumlah pejalan kaki dengan metode pencatatan volume pejalan kaki yang menyusuri dan menyebrang. Hal ini dapat digunakan untuk mengetahui tingkat volume pejalan kaki sehingga dapat memfasilitasi para pejalan kaki (khususnya para pelajar) yang menyusuri maupun menyebrang baik dari dan menuju sekolah sehingga dapat mengetahui aksesibilitas para pejalan kaki dalam berjalan dengan aman, nyaman dan selamat. Kebutuhan fasilitas pejalan kaki.

Setelah dilakukan survai maka didapat data volume pejalan kaki yang menyebrang dan menyusuri yakni: 


\section{Tabel 3 Data Pejalan Kaki}

\begin{tabular}{|c|c|c|c|c|c|c|}
\hline \multirow[t]{2}{*}{ No } & \multirow[t]{2}{*}{ Nama Ruas } & \multirow{2}{*}{$\begin{array}{l}\text { Panjang } \\
\text { Jalan yang } \\
\text { Disurvai } \\
\text { (m) }\end{array}$} & \multirow[t]{2}{*}{ Waktu } & \multicolumn{2}{|c|}{$\begin{array}{l}\text { Jumla orang } \\
\text { menyusuri } \\
\text { (orang) }\end{array}$} & \multirow{2}{*}{$\begin{array}{l}\text { Jml Orang } \\
\text { Menyebrang } \\
\text { (orang) }\end{array}$} \\
\hline & & & & $\begin{array}{l}\text { Kana } \\
\text { n }\end{array}$ & Kiri & \\
\hline \multirow{4}{*}{1} & \multirow{4}{*}{$\begin{array}{l}\text { JL. Raya PS } \\
\text { Kemis (SD } \\
\text { Kutajaya I) }\end{array}$} & \multirow{4}{*}{100} & 06:00-07:00 & 145 & 97 & 89 \\
\hline & & & 07:00-08:00 & 121 & 88 & 97 \\
\hline & & & $12: 00-13: 00$ & 74 & 91 & 101 \\
\hline & & & $13: 00-14: 00$ & 65 & 81 & 64 \\
\hline \multirow{4}{*}{2} & \multirow{4}{*}{$\begin{array}{l}\text { JL. Raya PS } \\
\text { Kemis (SMP I } \\
\text { PS. Kemis }\end{array}$} & \multirow{4}{*}{100} & 06:00-07:00 & 170 & 146 & 51 \\
\hline & & & 07:00-08:00 & 139 & 88 & 69 \\
\hline & & & 12:00-13:00 & 131 & 167 & 48 \\
\hline & & & $13: 00-14: 00$ & 107 & 89 & 45 \\
\hline \multirow{4}{*}{3} & \multirow{4}{*}{$\begin{array}{l}\text { JL. Raya PS. } \\
\text { Kemis (SD } \\
\text { SUKAASIH I) }\end{array}$} & \multirow{4}{*}{100} & 06:00-07:00 & 56 & 61 & 88 \\
\hline & & & 07:00-08:00 & 67 & 37 & 114 \\
\hline & & & $12: 00-13: 00$ & 43 & 76 & 97 \\
\hline & & & $13: 00-14: 00$ & 88 & 56 & 57 \\
\hline
\end{tabular}

Sumber hasil analisis

Dari table V.10 dapat diketahui besar volume pejalan kaki pada masing-masing ruas jalan yang menjadi focus ataupun konsentrasi pada lokasi penelitian.

Secara teknis, standar teknis trotoar meliputi:

1) Penempatan trotoar seharusnya lebih tinggi dari perkerasan jalan

2) Penempatan trotoar seharusnya diletakan pada sisi luar bahu jalan

3) Trotoar dapat ditempatkan pada sisi dalam drainase terbuka atau diatas saluran drainase yang sudah ditutup dengan plat beton.

4) Trotoar pada pemberhentian atau halte dapat ditempatkan dibelakang trotoar halte

5) Permukaan trotoar harus dibedakan dengan warna jalan dan dapat memiliki desain yang menarik

6) Trotoar seharusnya diberikan peneduh berupa tanaman atau konstruksi yang dibangun untuk melindungi pengguna.

7) Trotoar seharusnya memiliki ruang bebas minimal setinggi 2,5 meter.

8) Tinggi permukaan trotoar sesuai kondisi tata guna lahan

9) Lebar trotoar seharusnya berkisar antara 1,4 hingga 2,5 meter untuk dua orang sehingga dapat berjalan dengan nyaman.

Berdasarkan data hasil perhitungan dengan menganalisis jumlah pejalan kaki yang menyusuri jalan, maka dapat diketahui jenis trotoar yang sesuai. 
Tabel 4 Hasil Perhitungan Lebar Trotoar

\begin{tabular}{|c|c|c|c|c|c|c|}
\hline \multirow{2}{*}{ NO } & \multirow{2}{*}{ Nama Ruas } & \multicolumn{2}{|c|}{$\begin{array}{c}\text { Jumlah Orang } \\
\text { Menyusuri/Menit }\end{array}$} & \multicolumn{2}{|c|}{$\begin{array}{c}\text { Perhitungan Lebar } \\
\text { Trotoar (m) }\end{array}$} \\
\cline { 3 - 4 } & Kanan & Kiri & & Kanan & Kiri \\
\hline 1 & $\begin{array}{c}\text { JL. R. PS. Kemis } \\
\text { (SD Kutajaya I) }\end{array}$ & 2 & 1 & 1 & 1,1 & 1 \\
\hline 2 & $\begin{array}{c}\text { JL. R. PS. Kemis } \\
\text { (SMP I PS. } \\
\text { Kemis }\end{array}$ & 1 & 1 & 1 & 1 & 1 \\
\hline
\end{tabular}

Sumber hasil analisis

Dari hasil perhitungan seperti pada tabel tersebut maka dapat disimpulkan ketiga ruas jalan di Pasar Kemis memerlukan trotoar.

\section{Fasiltas Penyeberangan}

Berdasarkan kondisi eksisting Jalan Pasar Kemis belum tersedia fasilitas tersebut, sehingga untuk meningkatkan tingkat keselamatan bagi pejalan kaki dari hasil perhitungan harus dilakukan penyediaan fasilitas yang direkomendasikan. Penyeberangan pelikan merupakan penyeberangan sebidang yang dilengkapi dengan sinyal khusus untuk memberikan prioritas yang jelas kepada pejalan kaki. Hal ini dilakukan, khususnya pada penyeberangan sebidang dengan jarak pandang yang terbatas atau di jalan dengan volume dan berikut ini pedoman perencanaan penyeberangan pelikan bagi pejalan kaki :

a) Digunakan pada penyeberangan sebidang dengan jarak pandang yang terbatas;

b) Pada persimpangan, sinyal pelikan sebaiknya menjadi satu kesatuan dengan APILL persimpangan. Penggunaan sistem fixed time signal dengan memberikan fase khusus bagi pejalan kaki sangat disarankan, kecuali pada penyeberangan di ruas jalan;

c) Penerapan LTOR pada persimpangan tidak disarankan. Apabila LTOR diterapkan, sebaiknya gunakan sistem LPI (lead pedestrian interval) dimana sinyal pejalan kaki menyala terlebih dahulu sebelum sinyal hijau bagi kendaraan berbelok menyala. Interval minimum 3 detik atau sekurang-kurangnya waktu yang diperlukan penyeberang jalan untuk melewati 1 lajur lalu lintas (lajur yang digunakan untuk kendaraan membelok) dapat digunakan sebagai periode sinyal penyeberang menyala sebelum sinyal belok berubah hijau sesuai dengan pedoman teknis fasilitas pejalan kaki \& pesepeda yang dilansir dari pedoman pengoperasian Pelican Crossing di Indonesia yang diterbitkan Direktorat Jenderal Perhubungan Darat tahun 1997.

d) Tundaan pejalan kaki pada penyeberangan pelikan maksimum 60 detik. Waktu tundaan lebih dari 60 detik akan menyebabkan penyeberang jalan mulai menerobos sinyal yang ada. Pada persimpangan, tundaan dapat diminimalisasi dengan memperpendek waktu siklus atau mengurangi jarak penyeberangan; Penyeberangan pelikan di ruas jalan memiliki jarak sekurang-kurangnya $300 \mathrm{~m}$ dari persimpangan;

e) Penyeberangan pelikan di ruas jalan dilengkapi dengan tombol aktivasi (push button) dengan tinggi antara $900-1100 \mathrm{~mm}$. Pada ruas jalan dengan penyeberang jalan cukup tinggi (>100 penyeberang per jam), sebaiknya menggunakan sistem fixed time signal; 
f) Sebaiknya dilengkapi dengan fitur hitung mundur (countdown) dan sinyal suara. Sinyal Pelican Sinyal lalu lintas bagi penyeberang jalan terdiri atas 2 simbol. Sinyal "jalan” yang menggunakan simbol orang berjalan berwarna hijau dan sinyal "stop" yang menggunakan simbol orang berdiri berwarna merah. Sinyal ini memiliki 3 fase sebagai berikut :

g) Fase Merah Fase merah memberikan perintah untuk berhenti menyeberang jalan (stop).

h) Fase Hijau Fase hijau memberikan perintah untuk menyeberang dengan hati-hati (jalan).

i) Fase Hijau Berkedip Fase hijau berkedip memberikan peringatan akan berakhirnya fase hijau dan perintah agar penyeberang jalan yang berada di titik awal untuk berhenti menyeberang.

Gambar dibawah menunjukkan urutan fase APILL bagi kendaraan dan pejalan kaki pada penyeberangan pelikan. Waktu tunggu pejalan kaki dari mulai sinyal diaktifasi (tombol ditekan) sebaiknya tidak lebih dari 60 detik. Lamanya fase hijau pejalan kaki ditentukan berdasarkan interval waktu menyeberang, sementara fase hijau berkedip ditentukan berdasarkan kecepatan pejalan kaki yang diambil $1 \mathrm{~m}$ /detik (kecepatan rata-rata manula).

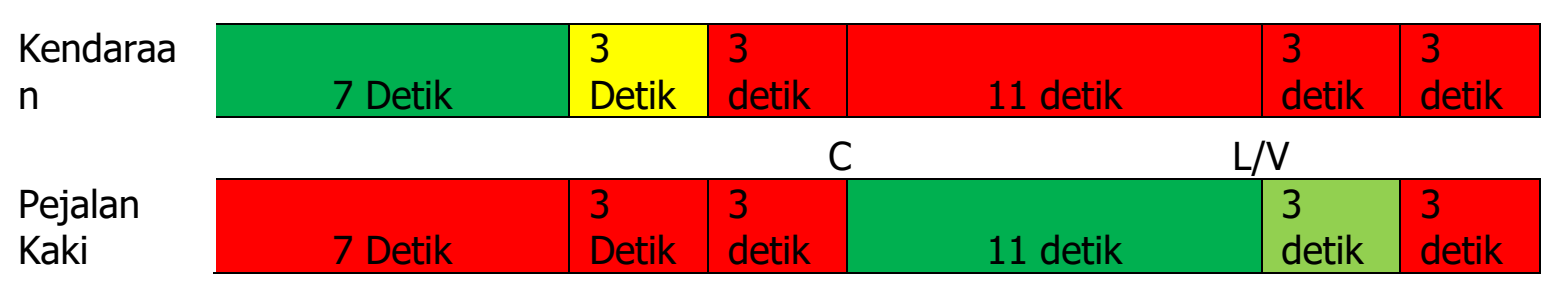

Dalam satu fase pelikan tidak boleh lebih dari 60 detik

Gambar 1 Fase Pelikan crossing

Keterangan :

(a) Waktu 7 detik pada waktu hijau kendaraan dan waktu merah pada pejalan kaki adalah ketentuan pada Dirjen Hubdat tahun 1997 tentang pengoperasian Fasilitas Pelikan di Indonesia

(b) Waktu 3 detik kuning pada kendaraan dan merah pada pejalan kaki juga merupakan ketentuan pada Dirjen Hubdat tahun 1997 tentang pengoperasian Fasilitas Pelikan di Indonesia

(c) Waktu merah 3 detik pada kendaraan dan pejalan kaki merupakan fase all red.

(d) Waktu 11 detik hijau pada pejalan kaki adalah berdasarkan perhitungan pada rumus waktu menyeberang (5.4) dan menimbulkan waktu merah pada waktu yang sama pada kendaraan

(e) Waktu 3 detik berwarna hijau muda merupakan waktu hijau berkedip agar pejalan kaki bergegas untuk melintas

(f) Dilanjutkan dengan 3 detik fase all red pada pejalan kaki dan kendaraan.

\section{Analisis Kebutuhan Jalur Sepeda}

Jalur sepeda yang disediakan secara khusus bagi pengguna sepeda dan/tempat yang digunakan bersama-sama pejalan kaki, dimana berfungsi untuk menjamin keselamatan dan keamanan bagi para siswa yang menggunakan sepeda untuk menuju sekolah.

Berdasarkan hasil survei dan analisis dilapangan perihal perhitungan jumlah pengguna sepeda bahwa untuk kebutuhan lajur sepeda masih belum dibutuhkan, hal ini menunjukan bahwa 
jumlah pengguna sepeda pada Jalan Pasar Kemis khususnya pada tiga sekolah masih belum memenuhi standar untuk diterapkan lajur khusus sepeda.

\section{Penentuan Titik Halte}

Penentuan spot halte Pada zona pendidikan yang dilakukan penelitian, halte dalam pengoperasiannya digunakan sebagai tempat menaikkan dan menurunkan pelajar. Berdasarkan Surat Keputusan Direktur Jenderal Perhubungan Darat Nomor 271/HK.105/DRJD/96 tempat pemberhentian kendaraan penumpang umum (TPKPU) terdiri dari halte dan tempat perhentian bus. Namun demikian dari tiga lokasi sekolah yang menjadi obyek penelitian ternyata tidak satupun dari tiga sekolah tersebut memiliki fasilitas pemberhentian kendaraan penumpang umum. Akan tetapi setelah dilakukan kajian terdapat spot lahan lokasi pemberhentian yang potensial dari ketiga sekolah tersebut yang berada di jalan raya pasar kemis. Sebagai persyaratan antara lain:
a. berada disepanjang rute angkutan umum/bus
b. terletak pada jalur pejalan kaki dan dekat dengan fasilitas pejalan kaki
c. diarahkan dekat dengan pusat kegiatan atau permukiman
d. dilengkapi dengan rambu petunjuk
e. tidak menggangu kelancaran lalu lintas

Tabel V. 18 Penentuan Jarak Halte

\begin{tabular}{|c|c|c|c|c|c|c|}
\hline No & Jalan & $\begin{array}{c}\text { Panjang } \\
\text { Ruas } \\
(\mathbf{m})\end{array}$ & TGL & Lokasi & Standar & $\begin{array}{c}\text { Digunak } \\
\text { n }\end{array}$ \\
\hline 1 & $\begin{array}{c}\text { Jl. Ps.Kemis (SDN } \\
\text { Kutajya I) }\end{array}$ & 150 & Padat & $\begin{array}{c}\text { Sekolah \& } \\
\text { Pemukiman }\end{array}$ & $300-500$ & 50 \\
\hline 2 & $\begin{array}{c}\text { Jl. Ps.Kems (SDN } \\
\text { SUKAASIH I) }\end{array}$ & 150 & $\begin{array}{c}\text { Campuran } \\
\text { Padat }\end{array}$ & $\begin{array}{c}\text { Sekolah \& } \\
\text { Pemukiman }\end{array}$ & $200-400$ & 20 \\
\hline
\end{tabular}

Sumber DJPD Nomor 271/HK.105/DRJD/96

Pada ruas jalan raya pasar kemis, telah dilalui tayek angkutan penumpang umum dengan kode trayek R 08 dengan R 15 Jurusan pasar kemis akan tetapi sepanjang jalan raya pasar kemis masih belum terdapat fasilitas pemberhentian angkutan umum .Selanjutnya setelah dilakukan identifikasi dan pengukuran lokasi terkait apakah jarak yang diusulkan sesuai dengan kemauan berjalan kaki memiliki lahan yang sesuai dengan tata guna lahan dan apakah terdapat lahan yang tersedia bagi halte tersebut untuk diterapkan. Pada ruas jalan raya pasar kemis tepatnya di dekat SDN Kutajaya terdapat lahan kosong yang bersebrangan dengan sekolah yang berjarak 50 meter dari sekolah, dan juga terdapat lahan yang berada di ruas jalan raya pasar kemis dekat SDN Sukaasih I yang berjarak 20 meter dari sekolah. Apabila ditinjau berdasarkan peraturan perihal pembangunan tempat pemberhentian kendaraan angkutan umum hal ini telah memenuhi standarisasi ketentuan pembangunan fasilitas tersebut yang menjadi obyek penelitian. Berikut merupakan gambar tata letak fasilitas halte pada ruas jalan. Lahan yang digunakan untuk pembangunan sarana fasilitas pemberhentian khususnya yang berada di ruas Jalan raya Pasar Kemis telah memenuhi kriteria baik ditinjau dari aspek keamanan, keselamatan sehingga ketertiban dan kelancaran dalam berlalu lintas tetap terjaga. 


\section{Penentuan ZOSS dan Perlengkapan Jalan}

Dicantumkan bahwa ZoSS merupakan salah satu fasilitas dalam mendukung terwujudnya konsep jalan yang berkeselamatan. Dalam Keputusan Direktur Jenderal Perhubungan Darat Nomor : SK.1304/AJ.403/DJPD/2014 tentang ZoSS dijelaskan bahwa ZoSS merupakan bagian dari kegiatan manajemen dan rekayasa lalu lintas berupa pengendalian lalu lintas dan penggunaan suatu ruas jalan dilingkungan sekolah. ZoSS bertujuan untuk mencegah terjadinya kecelakaan guna menjamin keselamatan anak disekolah. Padal lokasi tepatnya di jalan raya pasar kemis yang terdiri dari tiga sekolah dimana masing masing dari sekolah tersebut memiliki jumlah siswa lebih dari 50 sehingga ZoSS atau zona selamat sekolah dapat diterapkan Adapun kriteria dalam penetapan ZoSS ialah :

a. Jumlah lajur paling banyak 4 lajur.

b. Tidak tersedia jembatan Penyeberangan orang; dan

c. Sekolah yang memiliki akses langsung kejalanan yang memiliki jumlah siswa diatas 50 siswa.

Oleh karenanya, dari 3 sekolah dikawasan pendidikan Kecamatan Pasar Kemis harus disediakan fasilitas ZoSS untuk untuk mencegah terjadinya kecelakaan guna menjamin keselamatan anak disekolah.

Untuk meningkatkan keselamatan maka perlu dipasang rambu-rambu dikawasan RASS. Selain dari pemasangan rambu, terdapat pula pemasangan marka diantaranya marka gambar berbentuk sepeda, marka jalur sepeda warna hijau, marka larangan parkir atau berhenti marka panah dan lain lain. Dari sejumlah marka yang ada terdapat beberapa tanda marka larangan diantaranya marka larangan parkir atau berhenti dijalan sebagaimana dimaksud dalam pasal 39 PM Menteri No. 34 tahun 2014 dinyatakan dengan garis berliku-liku berwarna kuning. Garis berliku-liku tersebut memiliki panjang paling sedikit 1 meter dan lebar paling sedikit $10 \mathrm{~cm}$. marka larangan parkir atau berhenti dijalan ditempatkan pada sisi jalur lalu lintas. khusus pada marka larangan parkir atau berhenti ditempatkan sebelum fasilitas Penyeberangan depan SDN Kutajaya I, SMPN I Pasar Kemis maupun SDN Sukaasih I dengan tujuan agar penjemput atau pengantar tidak sembarangan berhenti/parkir. Hal ini terjadi karena mereka dituntut agar dapat parkir pada area drop zone/pick up zone point berupa fasilitas kiss and ride sehingga faktor keamanan, keselamatan, kelancaran dan ketertiban lalu lintas berjalan secara optimal serta angka dan risiko maupun tingkat fatalitas kecelakaan dapat menurun drastis.

\section{KESIMPULAN}

Dari penelitian tersebut diatas dapat disimpulkan bahwa fasilitas pejalan kaki terdiri dari dua kebutuhan fasilitas yaitu fasilitas pejalan kaki berupa trotoar maupun fasilitas Penyeberangan. Untuk fasilitas keselamatan berupa penambahan jalur sepeda belum perlu dilakukan pada ruas jalan yang menjadi lokasi penelitian karena belum memenuhi kriteria dalam analisis kebutuhan jalur sepeda. Semntara itu untuk kebutuhan halte pada objek kajian, terdapat lokasi berupa lahan yang cukup untuk pemberhentian khususnya pada sekolah SDN Kutajaya I yang berjarak 50 meter dari sekolah dan SDN Sukaasih I yang berjarak 20 meter dari sekolah. Adapun Untuk kebutuhan rambu berdasarkan hasil pengamatan kondisi eksisting dilapangan, dari ketiga sekolah tersebut belum terdapat rambu sehingga penulis menambahkan rambu yaitu rambu batas kecepatan minimum $30 \mathrm{~km} / \mathrm{jam}$, rambu lokasi pendidikan sekolah dan rambu menyeberang. Penambahan rambu sesuai dengan ketentuan ZoSS. 


\section{REFERENSI}

1. Undang-Undang Nomor 22 Tahun 2009 Tentang Lalu Lintas dan Angkutan Jalan, Direktorat Jenderal Perhubungan Darat.

2. Peraturan Direktur Jenderal Perhubungan Darat Nomor SK.407/AJ.401/DJPD/2014 Tentang Zona Selamat Sekolah.

3. Direktur Jenderal Perhubungan Darat Nomor SK.43/AJ.007/DRJD/1997 tentang Penyediaan dan Pemanfaatan Sarana dan Prasarana Ruang Pejalan Kaki. Direktorat Jenderal

4. Peraturan Menteri Perhubungan Nomor 13 Tahun 2014 Tentang Rambu Lalulintas.

5. Peraturan Menteri PU Nomor 03/PRT/M/2014 tentang Pedoman Perencanaan, Penyediaan, dan Pemanfaatan Prasarana dan Sarana Jaringan Pejalan Kaki di Kawasan Perkotaan, Kementerian Pekerjaan Umum.

6. Keputusan Menteri PU Tahun 2010 Tentang Pelatihan Perancangan Lajur Dan Jalur Sepeda, Kementerian Pekerjaan Umum.

7. Peraturan Menteri Perhubungan No 16 Tahun 2016 Tentang Fasilitas Jalur Pesepeda.

8. Keputusan Menteri Perhubungan No 65 Tahun 1993 Tentang Fasilitas Pendukung Kegiatan Lalu Lintas dan Angkutan Jalan.

9. Keputusan Menteri Perhubungan 1990 Tentang Petunjuk Perencanaan Trotoar.

10. Peraturan Menteri Perhubungan No 65 Tahun 1993 Tentang perencanaan trotoar.

11. Peraturan Pemerintah No 37 Tahun 2017 Tentang Jalan Yang Berkeselamatan.

12. Direktorat Jendral perhubungan darat Tahun 2014 Tentang Zona Selamat Sekolah.

13. Keputusan Menteri Perhubungan No 65 Tahun 1993 Tentang Fasilitas Pendukung Kegiatan Lalu Lintas dan Angkutan Jalan.

14. Peraturan Menteri Perhubungan No 13 Tahun 2014 Tentang Rambu Lalu Lintas.

15. Polres (2018) Data Kecelakaan Lalu Lintas di Kabupaten Tangerang 2018.

16. Badan Pusat Statistik Kabupaten Tangerang Tahun 2018,

17. Route Global (2015) Global Route Safety Partnership Indinesia 2015.

18. Andriayi, Rima. (2016) Konsep Rute Aman Selamat Sekolah Di Kawasan Pendidikan Kota Mataram, STTD. Bekasi.

19. Israita, W (2016) Analisis Kebutuhan Fasilitas Pejalan Kaki dan Pengguna Sepeda di Kawasan Selong Kabupaten Lombok Timur. STTD, Bekasi.

20. Mulyadi, A (2010) Pelatihan Perancangan Jalur Lajur Sepeda

21. Munawar, Ahmad (2009) Manajemen Lalu Lintas Perkotaan, Beta UGM, Yogyakarta.

22. Nurcahyadi, Harry (2017) Penerapan Konsep Rute Aman Selamat Sekolah di Kawasan Pendidikan Wlingi Kabupaten Blitar. STTD, Bekasi.

23. Nurhadi, Lutfi. (2015) Perencanaan Rute Aman Selamat Sekolah, STTD, Bekasi.

24. Tim PKL Kabupaten Tangerang (2018) Laporan Umum Tim PKL Kabupaten Tangerang, STTD, Bekasi. 